\title{
EL TESTIMONIO DE LA MUJER ANDINA Y SU PAPEL EN LA RECONSTRUCCIÓN DE LA HISTORIA: EL CASO DEL INFORME FINAL DE LA COMISIÓN DE LA VERDAD Y RECONCILIACIÓN (PERÚ)
}

\author{
THE TESTIMONY OF THE ANDEAN WOMAN AND HER ROLE IN \\ THE RECONSTRUCTION OF HISTORY: THE CASE OF THE COMMISSION \\ FOR THE TRUE AND RECONCILIATION (CVR) FINAL REPORT (PERU)
}

Gloria L. Macedo-Janto*

\begin{abstract}
A partir del vínculo, en Latinoamérica, entre las comisiones de la verdad y el discurso testimonial, este artículo explora el caso de la mujer andina en el Informe Final (IF) que presentó la Comisión de la Verdad y Reconciliación (CVR) en Perú como resultado del análisis de la época de violencia política. Estudia testimonios originales de mujeres de la zona andina de Ayacucho recolectados para dicho informe y también apartados específicos del IF que tienen como protagonista a las mujeres. En el contexto de las comisiones, el discurso testimonial de la mujer andina sirve para entender el documento presentado como IF y, también, la historia de Perú que se reconstruye con sus aportes.
\end{abstract}

Palabras claves: Comisión de la Verdad, Informe Final, mujeres andinas, discurso testimonial, narrativa de identidad nacional.

Based on the link between truth commissions and testimonial discourse, in Latin America, this article explores the case of Andean women in the Final Report (IF) presented by the Truth and Reconciliation Commission (CVR) in Peru as a result of the analysis of the political violence era. It is studied the original testimonies of women from the Andes in Ayacucho, which have been collected for this report; as well as, the specific sections of the IF that have women as their protagonist. In the context of the commissions, the testimonial discourse of the Andean woman is useful to understand the document presented as IF and the history of Peru that is reconstructed with its testimonies.

Key words: Truth Commission, Final Report, Andean women, testimonial discourse, narrative of national identity.

\section{Introducción}

Las comisiones de la verdad fueron creadas con el objetivo de evaluar las épocas de violencia que atravesaron países en crisis políticas. En Latinoamérica, sus alcances fueron particularmente rechazados o cuestionados. En Perú, desde antes de la publicación del IF de la CVR ya existía desconfianza de los ciudadanos y partidos políticos que no se sentían representados por lo que se afirmaría en ese documento. También, aunque más recientemente, desde el ámbito académico se cuestionan las cifras de víctimas y desaparecidos.

En este artículo se revisan las voces de las mujeres andinas en las audiencias públicas y en los testimonios escritos. Se han seleccionado, especialmente, testimonios que pertenecen a la zona sur central de Perú (Ayacucho), donde comenzó el accionar terrorista y se concentró el $40 \%$ de las víctimas reportadas; y que fueron transcritos y traducidos por la misma CVR. En ellos aparecen las voces de mujeres de diferentes edades que fueron víctimas o testigos en la época de violencia.

Se plantea que el IF promueve la voz de las mujeres y reconstruye los hechos por medio de sus miradas creando narrativas de identidad nacional. Con el uso del testimonio se reafirma la veracidad del discurso y este se carga de una intención de protesta. La historia personal de estas mujeres pasa a ser también historia pública. Así, estos discursos testimoniales, también, son, al mismo tiempo, relatos de la Historia. En ese sentido, el personaje femenino cumple dos funciones al mismo tiempo: ella será parte de lo que se cuenta y, a la vez, el ejemplo de lo que el discurso del IF va narrando.

Se pretende demostrar que el testimonio de la mujer andina resulta clave en la validación del discurso del IF de la CVR porque ella en su búsqueda

\footnotetext{
* Universidad Peruana de Ciencias Aplicadas. Lima, Perú. ORCID https://orcid.org/0000-0002-6227-9807.

Correo electrónico: macedo.gloria@gmail.com
} 
de respuestas por los desaparecidos y muertos, tiene la voluntad de contar. Es, además, estadísticamente, quien más sobrevivió a la época de violencia y porque ella misma fue víctima de discriminación, por su condición de mujer de los Andes.

\section{Las Comisiones de la Verdad}

Las Comisiones de la Verdad son organismos de investigación "creados para ayudar a las sociedades que han enfrentado graves situaciones de violencia política o guerra interna, a enfrentarse críticamente con su pasado" (Cuya, 1996). Su existencia ha tenido la intención de dar propuestas de reconciliación nacional y reparación a las víctimas. En el mundo se han creado alrededor de 40 comisiones de la verdad desde 1974, según Amnistía Internacional (2010), para casos en los que los países atravesaron tiempos de violencia. Estas comisiones parten de objetivos claros: "descubrir, clarificar y reconocer formalmente abusos del pasado; responder a necesidades concretas de las víctimas; contribuir a la justicia y al rendimiento de cuentas; hacer un esbozo de la responsabilidad institucional y [...] alentar la reconciliación" (Hayner 2008: 48). Estos objetivos, incluso, las han convertido en un "factor importante de democratización" (Lefranc 2009: 20).

En Latinoamérica, los informes de estas comisiones fueron controversiales. En Argentina, por ejemplo, se creó la CONADEP (Comisión Nacional sobre la Desaparición de Personas); en Chile, la Comisión de Verdad y Reconciliación; y en El Salvador, la Comisión de la Verdad. Sin embargo, la recepción de los informes, en general, no siempre ha sido positiva. Durante su trabajo de investigación y al finalizar este, tuvieron que surcar muchos escollos.

En Argentina, conforme la CONADEP avanzaba en sus investigaciones, sus miembros recibieron amenazas y "los acusaron de 'activar los odios y resentimientos, impedir el olvido, y no propiciar la reconciliación nacional"' (Cuya, 1996). Asimismo, en Chile, en 1992, se creó la Corporación Nacional de Reparación y Reconciliación para ejecutar las recomendaciones de la Comisión de Verdad y Reconciliación. Del mismo modo, en El Salvador, se realizó una investigación que terminó con recomendaciones al Estado acerca de reparaciones a las víctimas, aunque no se cumplieron.

Estas comisiones, además de recopilar información, sintetizar y analizar los episodios de enfrentamientos "se han constituido en mecanismos de expresión de los ciudadanos ultrajados y, también, en espacios de enfrentamiento y eventualmente de negociación entre las fuerzas políticas dominantes en un momento de transición" (Jave 2010: 95). Se insertan en la búsqueda de la verdad, en los tres sentidos que entiende May: I contend that there are three distinct types of truth claims made by truth commissions-descriptive (forensic) truth, moral truth, and normative truth (May 2013). Por eso, estas comisiones realizan un trabajo de memoria cuya intención es aprender del pasado para prevenir que se repitan los hechos en el futuro.

Para autores como Rodríguez, en estos procesos "las verdades que pueden ser producidas serán siempre parciales" (Rodríguez 2010: 591) del mismo modo que su legitimidad, que está condicionada a las relaciones de poder "en las que todos los actores están inmersos y que han condicionado el establecimiento de ciertas narrativas $-\mathrm{y}$ sus verdades- como marcos de interpretación dominantes" (Rodríguez 2010: 592).

Aquí, es importante distinguir, por ejemplo, el papel que se le otorga a los actores del conflicto y su participación en él. Si bien mediante los documentos que estas comisiones presentan se conoce la voz de los que fueron partícipes de esos episodios, la intención de conocer esas voces proviene del Estado, que, además, desde su posición, pretende, con estos documentos, garantizar la justicia y la equidad; ya que se establece como ente neutral y pacificador, después de sucedidos los hechos en los que también tomaba posición y fue, muchas veces, cómplice o, incluso, perpetrador.

\section{Aproximaciones al IF de la CVR Perú}

En el IF que se presentó en Lima, Perú, en 2003, a partir de 16.917 testimonios individuales y colectivos, que dieron 18.217 declaraciones, se concluyó que el número de personas muertas o desaparecidas fue de 23.969 (Comisión de la Verdad y Reconciliación [CVR] 2003: I: 123). Sin embargo, se estima que la cifra total de peruanos que pudieron haber muerto es de $69.280^{1}$. También se concluyó que entre la mayor cantidad de víctimas se encontraban los hablantes del quechua u otra lengua nativa. En el departamento de Ayacucho, región andina situada en el centro-sur del país, se concentró más del $40 \%$ de muertos y desaparecidos (CVR 2003: I: 120). 
Respecto de este informe existen trabajos de investigación donde se detallan con mayor especificidad la reacción de los medios de comunicación, incluso, desde antes de su publicación (Cf. Losada 2007, Zapata 2010, Arauzo 2011, Almeida 2011). En Ayacucho, la zona donde se originó la violencia terrorista, por ejemplo, gran parte de los medios de comunicación "reaccionó en contra de la Comisión de la Verdad, calificando al grueso de sus miembros como 'limeños', vinculados a ONG 'que lucran con el dolor del pueblo' o 'pseudointelectuales'” (Zapata 2010: 19). Aquí se exponía claramente un discurso de rechazo frente al "otro" que no tiene la capacidad de representación, y que se configura como un sujeto lejano.

Saucedo destaca que las reacciones fueron variadas. Cuenta que la revista Ideele mostró los resultados de una encuesta en la que "la mayoría de limeños de todo origen socioeconómico creía en la veracidad de este trabajo" (2012: 28). Pero algunos grupos políticos como el APRA cuestionaron el cálculo de víctimas estimado. "Partidos políticos $\mathrm{e}$, inclusive, algunos miembros de comunidades andinas y ronderos [énfasis original] protestaron por diversos motivos (el destino de las reparaciones monetarias, por ejemplo)" (Saucedo 2012: 28).

Por otra parte, Zapata menciona que se construyó un discurso de "otredad invertida" cuando el periódico La Calle publicó lo siguiente frente a la elección de los comisionados, quienes eran intelectuales de la capital:

¿Cómo van a entender a los hermanos de Aqomarca, Lucanamarca, Erusco, Pallqa, Manallasaq o Incaraqay, si no podrán interpretar desde su pedestal académico de honras y medallas occidentales el real espíritu de los testimonios que deben recogerse de primera mano, además de con el cerebro, también con el corazón?" (Cit. por Zapata 2010, 21).

Este rechazo explica, en parte, por qué la reticencia a aceptar el discurso de la CVR. Ramos dice que uno de los motivos por los que el IF no ha calado en la sociedad de manera efectiva es porque proviene de aquello que Rama denominó la "ciudad letrada"; "el IF no solo proyecta sobre la realidad un discurso categórico y sofisticado, sino que impone-gracias a la estructura de poder en el que se consolida- su única visión histórica de la realidad" (2009: 57). Podría considerarse que algunos miembros de la comisión sí pertenecen a esa llamada ciudad letrada, pero la organización de la misma y la redacción del Informe obedeció a principios del Estado.

Los comentarios negativos se extendieron en la prensa cuestionando el estatus u orientación política de los comisionados y, por esta razón, se cuestionaba el IF de la CVR. Otra de las razones mencionadas era el resentimiento que podía causar al azuzar heridas aún no curadas y, finalmente, que no se tomaron en cuenta los puntos de vista de todos los participantes (Zapata 2010: 56). Por ejemplo, con motivo del $10^{\circ}$ aniversario del IF, el periódico digital Altavoz, de clara oposición al gobierno y de filiación política ligada a grupos de poder, publicó lo siguiente: "El informe de la CVR no dijo la verdad ni 'reconcilió' a los peruanos tras aquel sanguinario episodio de nuestra historia, sino que destrozó la memoria colectiva y la convirtió en un credo ideológico, en el cual solo cabe la versión de unos pocos" (Tudela 2013).

Muestras del escepticismo con que fue tomada esta investigación, estas reacciones se evidenciaron en la prensa nacional. Aunque aún mucha gente desconoce el contenido del IF, las redes sociales y la Internet hacen eco de ciudadanos disgustados con los resultados propagados por la CVR. Esa disconformidad se manifiesta, también, en el ámbito académico con el cuestionamiento de la metodología de investigación. Incluso, se han propuesto otras cifras de desaparecidos o víctimas que distan mucho de las originales (Rendon 2019).

En Perú, aún hoy, casi veinte años después de la entrega del IF, se pueden encontrar comentarios adversos a la comisión de la verdad. Ante ello, varios intelectuales han manifestado su conformidad con el IF para acallar las voces de desconcierto ante las conclusiones del organismo encargado de develar las causas de veinte años de violencia. Incluso, ante la indiferencia que provocó a las instituciones que debían asumir dichas conclusiones para tomar medidas correctivas y de reparación con las víctimas.

\section{El discurso oral y el discurso testimonial en el IF}

La CVR propició la realización de las audiencias públicas con el objetivo de escuchar a las víctimas que accedían a mostrarse en público para simbólicamente devolverles su dignidad. Estas "son sesiones solemnes en las que los comisionados 
reciben directamente, ante la opinión pública nacional, el testimonio de víctimas o testigos, respecto de hechos que hayan afectado gravemente a la víctima y a su grupo familiar o social, o que por su magnitud y complejidad hayan marcado al país" (CVRa 2014). En esos discursos orales, los hablantes matizan su participación de acuerdo con sus propias características y, además, por la reacción que va generando la emisión de su propio discurso ante el auditorio mientras interactúa con este, pues una de las peculiaridades del discurso oral es que se va construyendo mientras se realiza. Como dice Zumthor, "La oralidad no se reduce a la acción de la voz. Como expansión del cuerpo, este no la agota. La oralidad implica todo lo que, en nosotros, se dirige al otro, ya sea un gesto mudo o una mirada" (Zumthor 1991: 202). Así, incluso, en un discurso oral, una frase mal estructurada sintácticamente, tendrá igual o más valor por el tono con el que se dice y la modulación de la voz o por los gestos que la acompañan. No se puede obviar que el lenguaje oral viene cargado de otros elementos que van desde el énfasis en ciertas palabras hasta el empleo de movimientos y gestos que reproducen o afianzan el significado de lo que se expresa verbalmente. Tanto en el lenguaje oral como en el escrito operan ciertas reglas que permiten su expresión, como ocurre, en el caso de este último, con las normas gramaticales de cada lengua, por ejemplo. Pero, el lenguaje oral es más independiente, pues en él, lo importante es que los interlocutores entiendan lo que se quiere comunicar y no, necesariamente, que se respeten las normas de construcción de los enunciados (Macedo 2008: 53-54).

Son dos los ejemplos más resaltantes de participaciones de mujeres en las audiencias públicas. El primer testimonio oral ${ }^{2}$ es de Angélica Mendoza de Ascarza (CVRa, 2015). Emite su testimonio en quechua y se entiende el dolor que le causó la desaparición y búsqueda de su hijo Arquímedes, desde julio de 1983. El segundo testimonio, esta vez en español, es de la víctima de violación sexual Giorgina Gamboa (CVRb, 2015). Ella cuenta llorando los hechos ocurridos el 2 de enero de 1981. Narra cómo fue ultrajada durante toda la noche, pidiendo ayuda, pero sin ser escuchada. Manifiesta su terrible experiencia al haber sido violada por siete militares "sinchis"3 en su propia casa. "Quería matarme... quería morirme", dice y termina expresando su frustración ya que ni siquiera puede pedir justicia para las víctimas.
La misma CVR admite que "las audiencias públicas fueron una de las actividades más impactantes y probablemente controversiales" llevadas a cabo. Algunos sectores las aplaudieron con entusiasmo y las consideraron un paso positivo. Otros las consideraban denigrantes o sensacionalistas (CVRb 2014). De estos mismos testimonios, dice Ramos que "llevan en el centro la existencia de un conjunto físico, armónico e indivisible, atentado y golpeado durante la lucha armada: el cuerpo" (Ramos 2009:89). A esta característica la llama "corporificación", que es "la persistencia del valor simbólico mismo de los testimonios luego de pasar, primero, por políticas de represión de Estado; luego, por el caos de la violenta lucha armada de las rondas mismas y el PCP-SL ${ }^{4}$; y finalmente, por el corsé espiritual impuesta (sic) por la CVR" (Ramos 2009:120). Sin embargo, en el caso del IF, con el discurso escrito, armonizado, la CVR logra mantener una autoridad como enunciante principal, que se extiende más allá de la "corporificación" del testimonio; y se vuelve gran organizador de voces y cuerpos testimoniales.

Desde los estudios literarios, Ramos hace una aproximación al universo que se construye en el discurso de la CVR. Sostiene que estos testimonios son de personajes atormentados "en tensión entre vencer o no su subalternidad, salen ahora no por la vía del encuadernado público y su editor, sino a través del Archivo: gran espacio físico nacional en donde permanecen como ecos que esperan retumbar" (Ramos 2009:31). La relevancia de la mención al archivo "radica en su condición de ser un lugar de enunciación que instala y legitima discursos en competencia sobre la cultura y la historia en las Américas" (Cortez 2018:33). Sobre esos discursos, Ramos dice que el testimonio "es solo el paso de las voces del auditorio a otro soporte más: el papel" (2009:114), pero con esta afirmación desconoce el trabajo de edición inherente a cualquier publicación. Además, el editor de testimonios tiene como tarea rescatar y mantener el carácter de denuncia de estos; así como proyectar el efecto de catarsis en el discurso. De ese modo, el texto escrito se vuelve independiente de su antecesor oral. En ese sentido, al invocar las voces de otros para afirmar la voz propia (la del gran editor), el IF, como texto escrito trasciende. Por esta razón, la transcripción de los testimonios no son de ninguna manera un traspaso mecánico al papel. El testimonio oral no sufrió un paso objetivo al papel, allí hubo también 
una mediación desde la edición, la elección del espacio adecuado para colocar el testimonio en el propio informe. Ese paso al papel obedece al contexto político. Hay una preocupación editorial, que pretende dar sentido al discurso recogido vía oral por distintos actores en diferentes momentos. Y esto se puede corroborar cuando se contrastan los testimonios completos recopilados por la CVR, cuyas transcripciones se encontraban originalmente en la Defensoría de Pueblo, con las versiones citadas en el IF. Evidentemente, no se trata de un libro a cargo de un editor literario (quien va manejando los datos para que su relato resulte más atractivo, verosímil o ficcional), pero sí de discursos tomados del testimonio y usados como fuente para elaborar el texto escrito.

Para la construcción del IF, una de las voces más conscientes fue de las mujeres que decidieron testimoniar para la CVR. Cuando ellas deciden salir del silencio y cuentan a los representantes de las autoridades lo que su memoria guarda, están saliendo del espacio privado, para hurgar en sus recuerdos y, además, salen del espacio limitante de su comunidad para hacer conocer sus opiniones al mismo Estado. Esto no había ocurrido antes. Era la primera vez que se propiciaba escuchar sus voces. Y las circunstancias eran atípicas, pues eran ellas mayoritariamente las que habían sobrevivido a la época de violencia.

\section{Implicancias del testimonio en el IF}

Varios autores han definido el testimonio (Cf. Beverley 1987,1992; Jara y Vidal 1986; Theodosíadis 1996) especialmente con el significado que tiene para los estudios de las ciencias sociales en América Latina. En torno a su conceptualización se iniciaron debates que abrieron el campo de estudios, incluso hacia lo literario. Ya lo esgrimía Beverley cuando señalaba que "parte de la razón de ser del testimonio es que escapa a nuestras categorizaciones usuales, y en particular a la distinción entre lo literario y lo no literario" (Beverley 1987). Esta afirmación atraviesa los debates en torno al testimonio desde el ámbito discursivo. También se entiende que el testimonio "es una 'narración de urgencia' [...] Su punto de vista es desde abajo. [...] Pero aun cuando no tiene una intención política explícita, su naturaleza como género siempre implica un reto al statu quo de una sociedad dada" (Beverley 1987). Entonces, testimoniar es ya rebelarse frente a las estructuras establecidas.

Además de la desconfianza al discurso proveniente de "la ciudad letrada", la reticencia frente al discurso del IF se alimenta cuando se considera que es el testimonio uno de los principales recursos de los que se ha valido la CVR para la redacción del IF. Y el empleo del testimonio no tiene la intención de novelar la época de violencia que se retrata; sino de organizar esta mediante la visión de mujeres y hombres que sobrevivieron a esos años. El discurso del IF es un texto de no ficción proveniente del campo de las Ciencias Sociales, que pretende como la comisión a la que pertenece, ser objetivo en la búsqueda de la verdad.

La finalidad era, por medio de sus miradas ${ }^{5}$, reconstruir los hechos, pues cuando se trabaja con testimonios, como dice Prada, se asume que todo discurso testimonial "es siempre referencial y pretende un valor de verdad" (1986: 9). Por eso, el hecho de valerse de los testimonios e incluirlos en el IF implica, principalmente, dos cosas. Por un lado, reafirmar la idea de verdad, de que lo que se está contando es siempre verdadero, por varios ejemplos de personas que dan fe de los acontecimientos y de las que intervinieron. Como afirma Beverley, en ese sentido, "el testimonio no es una obra de ficción: mejor dicho, su convención discursiva (como sugiere la connotación jurídica o religiosa de 'dar testimonio') es que representa una historia verdadera, que su narrador es una persona que realmente existe" (1987: 11). Esto produciría el llamado efecto de veracidad que ocasiona sea percibido como no ficcional. Y, por otro lado, implica que el discurso se carga de una intención de protesta frente a una situación conflictiva, porque en el testimonio el eje no es el personaje que enfrenta situaciones conflictivas, "sino una situación social problemática que el narrador testimonial vive o experimenta con otros" (Beverley 1987: 11).

Se recurre al testimonio porque como dice Casaus, este "a través de sus diversas líneas creativas, realiza la importante función de rescatar la memoria colectiva de nuestros pueblos" (1986: 330). A pesar de lo subjetivo inherente al discurso de los testimoniantes y, en consecuencia, del discurso de la CVR, una de las causas en los problemas de la recepción del IF es el grado de verdad que puede representar el hecho de ser las ciencias sociales las encargadas de evaluar este proceso. Al igual que las ciencias humanas, la desconfianza de la objetividad 
de sus afirmaciones ha sido cuestionada por no pertenecer a las llamadas ciencias exactas. Habría que recordar lo que afirma Rorty al respecto:

\begin{abstract}
Si decimos que la sociología o la crítica literaria no son ciencias, meramente querremos decir que la cantidad de consenso entre los sociólogos o los críticos literarios sobre lo que se considera una obra importante, que necesita continuación, es menor que, por ejemplo, entre los microbiólogos (Rorty 1998: 63).
\end{abstract}

El testimonio como discurso es la expresión de la memoria, personal y colectiva, que recrea sus experiencias. Y describe la manera cómo son recordados los sucesos que han marcado al personaje que le tocó vivir episodios que, además de determinar su historia personal, también hicieron lo mismo con la de todo un pueblo y, en este caso, la de todo un país.

El reto de la CVR es doble cuando a la tarea de intentar decir verdaderamente lo que ocurrió, se suma el reto de lograr que su discurso sea creído y que este sea verosímil, en el sentido que proponía Aristóteles ${ }^{6}$. Así, aunque las investigaciones de la CVR explicadas en el IF evidencian verdades de la historia como sociedad peruana, la duda inicial ante el número de víctimas, la negación de la existencia de la discriminación en el país-aunque esta ha sido reconocida como una de las principales causas de la violencia-no legitiman su discurso. Esto se debe, en parte, a que no existe la confianza en estas verdades que provienen de un estudio sociológico, que escapa del modelo de otros discursos en los que sí depositamos nuestra confianza. A propósito, dice Geertz que "Los etnógrafos necesitan convencernos [...] no solo de que verdaderamente han 'estado allí' sino de que [...], de haber estado nosotros allí, hubiéramos visto lo que ellos vieron, sentido lo que ellos sintieron, concluido lo que ellos concluyeron" (Geertz 1989: 26). Al tema de la desconfianza a la voz proveniente de "la ciudad letrada" se suma la desconfianza al trabajo del investigador social.

\section{Narrativas de identidad nacional}

El IF supera el carácter confesional para volverse, potencialmente, discurso de la historia y narrativa de identidad nacional, en el sentido que entiende Silva Santisteban cuando, al referirse a los testimonios de las comisiones, dice que estos que se llevaron a cabo en países de Latinoamérica cuestionan la noción y los límites de lo que se entiende por literatura "no para disidir por el simple hecho de negar o interrumpir una tradición, sino porque -superando lo documental, confesional e instructivo-judicial de la prueba o el alegato- estos testimonios son "narrativas de identidad nacional" (2008: 78). Así, pese a los cuestionamientos, estos discursos testimoniales, también, son, al mismo tiempo, relatos de la Historia. En ese sentido, la labor de la CVR, como fue el caso de otras comisiones, fue evidenciar lo que había sucedido en el país según los testigos.

Uno de los personajes clave en todo este proceso de violencia fue la mujer -en el sentido de personaje para $\mathrm{Hamon}^{7}$-, ya sea como miembro obligado de apoyo al senderista o al ejército, por voluntad propia, o como eje del sustento y defensa de su entorno familiar. Si bien el IF no está basado solo en la participación del personaje femenino, sí lo toma en cuenta para desarrollar y sustentar especialmente algunas secciones, como es el caso del apartado del tomo VIII, capítulo 2, sobre "El impacto diferenciado de la violencia", donde se habla de género y de su condición andina; también, en el tomo VI, capítulo I, sobre "Patrones en la perpetración de los crímenes y de las violaciones de los derechos humanos" se dedica un apartado a las violaciones sexuales contra la mujer. Además, del total de personas que brindaron su testimonio a la CVR, el $54 \%$ fueron mujeres y el $46 \%$ varones (CVR 2003: VIII: 50). La mayoría de ellas eran jóvenes y quechuahablantes. Por eso, para esta investigación se revisaron las versiones originales de los testimonios, además de los que aparecen publicados en el IF. Los seleccionados pertenecen a la zona sur central del Perú (Ayacucho) y fueron transcritos y traducidos por la misma comisión. En ellos aparecen las voces de mujeres de diferentes edades y que fueron víctimas o testigos en los años de 1980 al 2000.

En el IF el discurso de la mujer andina nos llega a partir de respuestas o citas que se encuentran diseminadas en el texto. Como se plantea desde antes de su ejecución, este informe está diseñado para desenmarañar los hechos y llegar a la verdad. Así que las citas incluidas también tienen esa intención. Para lograr esto, debe haber una selección de lo que este personaje dice, ya que no todo puede ser copiado literalmente, y se utiliza para completar 
alguna idea que contribuye a entender mejor el camino que ha tomado el discurso. En ese sentido, su testimonio es importante para verificar lo que se quiere demostrar, resultado de las investigaciones realizadas anterior o paralelamente. Así, la mujer (al igual que los otros personajes que aparecen en el IF) cumple dos funciones al mismo tiempo: ella será parte de lo que se cuenta y, a la vez, el ejemplo de lo que el discurso va narrando.

Es importante recordar que, desde antes, las relaciones entre mujeres y hombres en Perú no eran equitativas, por eso "La violencia exacerbó estas diferencias y las relaciones se caracterizan por la desigualdad, las relaciones jerárquicas y la discriminación" (CVR 2003: VIII: 50). A propósito, Manrique señala que "tiene que reconocerse que la muy escasa solidaridad de una significativa fracción de la sociedad peruana con los indígenas que fueron las víctimas principales del conflicto en cierto modo hizo posible que sucedieran los hechos que ocurrieron" (2003).

La que aparece en el discurso de la CVR es un personaje que expone sus vivencias y expresa sus sentimientos cuando recuerda los hechos vividos en la época terrorista. Su relato no pretende ocultar lo que sintió y tampoco lo que siente en el momento en el que recuerda los hechos que son, en su mayoría, dolorosos y traumáticos. Ella, como se evidencia en las audiencias públicas, y los otros testimonios recogidos por la CVR, narra lo vivido como si lo experimentara de nuevo y lo actualiza con su memoria reviviendo los hechos de violencia. De ese modo, para ella, los acontecimientos se viven dos veces: cuando en realidad ocurrieron, y cuando los actualiza en su memoria y los narra. Además, cuando escarba en los recuerdos y da a conocer su punto de vista, se traslada de un plano personal a un plano social. Su historia personal pasa a ser también historia pública. No solo porque desde que emite su testimonio, su historia será conocida por los demás, sino porque con su versión de los hechos se va reconstruyendo la propia historia de los 20 años de violencia del país.

El testimonio de la mujer andina juega un papel importante en la validación del discurso del IF de la CVR, pues con su palabra recoge el dolor de todas las mujeres víctimas, quienes algunas veces cumplieron el papel de madre, en otras ocasiones el de esposa, conviviente, hija o viuda. La mujer es testigo clave no solo porque le tocó encarnar un papel difícil, sino porque cuenta de manera especial sus recuerdos, de modo que los actualiza con la narración que hace en primera persona y, con ello, ayuda a construir el discurso del IF. El documento presentado por la CVR no es un libro escrito o creado por ella, ni tampoco pretende colocarla como personaje principal ni contar todos los hechos desde su punto de vista. El IF es un documento que selecciona partes específicas de su testimonio para dar a conocer un objetivo de la CVR. Dice Salomón Lerner Febres: "Se nos pidió investigar y hacer pública la verdad sobre los veinte años de violencia de origen político iniciados en el Perú en 1980" (CVR 2003: I: 29). Así, lo que se narra podría estar supeditado a las preguntas planteadas y a la dirección establecida con anterioridad por los miembros de la CVR.

En los testimonios originales que fueron recogidos entre 2002 y $2003^{8}$ que las mujeres brindaron a los recopiladores de la CVR, se aprecia que existe la voluntad de los entrevistadores de conocer las circunstancias en las que se originaron los hechos de violencia. Estos sucesos, a veces, podían ser muy crudos:

"se nos quitó nuestro madre para que asista
a la Asambleas y llorábamos porque éramos
niño, en esa Asambleas lo mataron a mis tíos
que eran autoridades y que los exigían estar
en la Asambleas y reventaban dinamitas y
así mi papá ya no estaban (Llanto). Es difícil
no tener nada, hemos sufrido llanto, hemos
pasado días sin comer solamente en base
de coca..." (CVR testimonio 200657: 20).

A lo largo del documento se puede apreciar cómo la testimoniante se ve enfrentada con un pasado que aún hasta ahora le causa dolor. Algunas de ellas señalan tener "cólera" hasta el momento de la entrevista y explican cómo fue que desaparecieron todos los hombres, como cuenta Alejandra Flores, tal es así que en su pueblo solo quedan mujeres y "viejitos" (CVR testimonio 200550:25). Esto implicó la migración y búsqueda de nuevos espacios en los que los "contenidos culturales se transforman" e, incluso, se resignifican (García, Vega 2020: 152).

Las testimoniantes pueden ser víctimas o testigos. A veces, incluso se las registra como "testigo directo" si fueron ellas mismas las que presenciaron los hechos. Existen casos de mujeres que perdieron a algún miembro de su familia, esposo, hijos o hermanos. 
Las edades varían. En algunos casos, son mujeres de 23 años, y en otros casos, son casi octogenarias.

Su papel en la comunidad de los Andes es el de agente transmisor de cultura, ella "cumple con su rol endoculturador frente a las nuevas generaciones haciendo que poco a poco vaya familiarizándose con las actividades propia de su identidad genérica (feminidad) y su herencia cultural" (Viera, 2009: 122). Asimismo, su rol como adulta se sustenta en una unidad doméstica que los respalda y complementa (Mendoza, et al. 2020: 143).

Una de ellas de 30 años, socia de un club de madres, dice: "Nosotros quisiéramos que nos apoyen... no encontramos trabajo ni en las casas, peor si somos de la chacra, somos personas desempleadas, las mujeres mucho menos no encontramos trabajo" (CVR testimonio 200670: 41). Mediante los testimonios, vemos que las consecuencias de la violencia se extienden en el tiempo. A una de ellas, de 76 años, el entrevistador le pregunta cómo le afectó la desaparición de su hijo y ella llora. Ellos conversan así: "No se olvida usted", le pregunta él. "No, espero no olvidar", le contesta ella (CVR testimonio: 200710).

Varias de las testimoniantes agradecen la oportunidad de poder contar su historia, pero también hacen notar que los estragos continúan, no solo en su situación económica, sino también en sus memorias, en sus recuerdos que son todos negativos y traumáticos. Una de ellas narra la muerte de su hijo de 19 años, a quien le pusieron un cartel que decía "Por soplón" "Así mueren los soplones", que era el mensaje que solían dejar los subversivos a quienes ellos creían que los traicionaban. Esta madre hace notar los daños psicológicos y económicos que atraviesa debido a lo ocurrido, y menciona que nunca ha recibido ayuda de nadie, a pesar de lo sucedido (CVR testimonio:200837). El trabajo del Estado, en ese sentido, había sido nulo e indiferente con las víctimas. Su discurso es, entonces, no solo un testimonio que cuenta, sino que también reclama justicia.

En muchos testimonios, las mujeres no saben a quién culpar de la muerte o desaparición de sus familiares. No saben si fueron los terroristas o los militares. Una de las mujeres de 39 años cuenta la muerte de su hermano y de su papá. Cuando le preguntan "¿qué problemas ha ocasionado a la comunidad? ¿Intentaron matar a los terroristas, los militares?", ella responde: “De los dos, nos escapábamos asustados" (CVR testimonio: 200859). En otro testimonio se narra cómo mataron al papá de una niña de 6 años: "Siempre mi papá hablaba en contra de ellos (partido terrorista) es por eso que ya lo habían marcado para matarlo (caminaba a escondidas)" (CVR testimonio 201134). Por otro lado, otra de las tantas historias trágicas, la vivió su madre, cuando después volvió a comprometerse y su nuevo esposo también fue asesinado.

Se encontró el testimonio de una mujer de 36 años. Ella, en realidad, fue a denunciar la muerte de un familiar, pero terminó contando su propia violación, de la que fue víctima después de ser amenazada de muerte. Es curioso ver que, al término de este testimonio, esta mujer no pide justicia para ella, sino que reclama por el cadáver de su conviviente: "Parecía, como nosotros no lo hemos enterrado me parece que él existe, vive, eso entonces yo quiero acabar con eso, con ese, por lo menos decir, que sí se ha enterrado" (CVR testimonio 201093: 33).

En los testimonios recopilados por la CVR, algunos de ellos incluidos en el IF, aparece la voz de la mujer andina dispuesta a contar, voz que representa su papel en su comunidad, cuya enunciación antes no había sido representada ni promovida desde el Estado, debido a su rol estuvo excluida del ámbito político (Vásquez 2018: 54). Incluso, en otros testimonios, no había tenido la oportunidad de representarse. Pero "una de las características de las relaciones jerárquicas es que son dinámicas y pueden ser transitorias" (Carrasco, Gavilán 2014: 178). Por eso, ella, pese a los cuestionamientos al discurso de la CVR, en esos testimonios, desde esta nueva posición, con su voz, cumple con la función de reescribir la historia.

\section{Conclusiones}

Para entender la época de violencia, en Perú como en otros países de América Latina, se instauró una comisión especializada. Sin embargo, la recepción del IF elaborado por esta comisión provocó reacciones adversas que se evidenciaron en los medios de comunicación.

El IF de la CVR fue elaborado con la participación de los testimonios de las víctimas. En él, la mujer, especialmente la mujer andina, es un personaje clave que fue, también, víctima de la violencia. Este personaje, muchas veces, es la principal fuente con la que se cuenta, ya que los demás desaparecieron o fueron asesinados. A su 
voz se accede a partir de testimonios orales que se reprodujeron en las audiencias públicas y en los recogidos originalmente por la CVR (que luego aparecen diseminados en el IF). En el caso de las audiencias públicas los testimonios, además del contenido que describen, se caracterizan por la performance de los testimoniantes al momento de sus presentaciones. Diferente es el caso de los testimonios escritos. El paso de lo oral a lo escrito tiene ciertas características que se explican por el papel que el mediador (antropólogo, recopilador, investigador, etc.) asume, que ha sido motivo de discusión y debate acerca del discurso testimonial, que lo hace, en tanto discurso, analizable desde las categorías literarias.

Los testimonios incluidos en el IF reconstruyen la historia peruana en los años de conflicto, ya que su aparición no es gratuita y no solo se debe a la necesidad de refrendar lo dicho mediante las voces de los propios protagonistas, sino que se configura, también, al mismo tiempo, como una estrategia discursiva que permite la lectura del informe como documento que contiene la verdad. Es especial la participación de la mujer andina, cuya voz es promovida desde el Estado, por primera vez, para la construcción de este documento oficial.

\section{Referencias Citadas}

Almeida, C.

2011 Análisis crítico de los discursos sobre las tragedias de Uchuraccay, Lucanamarca y Putis en la prensa escrita de Perú. Tesis de Licenciatura. UNMSM, Lima.

Arauzo, V.

2011 El aporte de la prensa a la difusión del trabajo de la Comisión de la Verdad y Reconciliación. Tesis de Licenciatura. UNMSM, Lima.

Beverley, J.

1987 "Anatomía del testimonio". Revista de Crítica Literaria Latinoamericana, 13(25):7, doi:10.2307/4530303

Beverley, J.

1992 "Introducción". Revista de Crítica Literaria Latinoamericana, 18(36):7, doi:10.2307/4530620

Carrasco, A. y Gavilán, V.

2014 "Género y etnicidad. ser hombre y ser mujer entre los aymara del altiplano chileno". En Diálogo Andino 45: 169-180. Universidad de Tarapacá. Chile.

Casaus, V.

1986 "Defensa del testimonio". En Testimonio y literatura, editado por René Jara y Hernán Vidal Ed. Universidad de Minnesota, Minneapolis.

Cortez, E.

2018 Incendiar el presente. La narrativa de la violencia política y el archivo (1984-1989). Campo letrado, Lima.

Cuya, E.

1996 Las comisiones de la verdad en América Latina se.iii. KO'AGA ROÑE'ETA (1 abril), http://www.derechos.org/ CVR koaga/iii/1/cuya.html (20 mayo 2015).

2002 Testimonio 200550. Centro de Información para la memoria colectiva y los derechos humanos. Defensoría del Pueblo, Lima.

CVR

2002 Testimonio 200657. Centro de Información para la memoria colectiva y los derechos humanos. Defensoría del Pueblo, Lima.

CVR

2002 Testimonio 200670. Centro de Información para la memoria colectiva y los derechos humanos. Defensoría del Pueblo, Lima.
CVR

2002 Testimonio 200710. Centro de Información para la memoria colectiva y los derechos humanos. Defensoría del Pueblo, Lima.

CVR

2002 Testimonio 200837. Centro de Información para la memoria colectiva y los derechos humanos. Defensoría del Pueblo, Lima.

CVR

2002 Testimonio 200859. Centro de Información para la memoria colectiva y los derechos humanos. Defensoría del Pueblo, Lima.

CVR

2002 Testimonio 201093. Centro de Información para la memoria colectiva y los derechos humanos. Defensoría del Pueblo, Lima.

CVR

2002 Testimonio 201134. Centro de Información para la memoria colectiva y los derechos humanos. Defensoría del Pueblo, Lima.

CVR

2003 Informe Final. Lima.

CVRa

2014 Audiencias públicas, http://www.cverdad.org.pe/ apublicas/audiencias/index.php (20 abril 2015).

CVRb

2014 El impacto de las audiencias públicas en los participantes, http://cverdad.org.pe/apublicas/audiencias/impacto. php (20 abril 2015).

CVRa

2015 Angelica Mendoza de Ascarza (20 abril), https://www. youtube.com/watch? $\mathrm{v}=4 \mathrm{xpkXNxm558}$ (agosto 2015)

CVRb

2015 Georgina Gamboa García. Lima (1 mayo), https:// www.youtube.com/watch?v=4czj3-5bheQ (30 mayo 2015).

Eco, U.

1996 Seis paseos por los bosques narrativos. Lumen, Barcelona.

García, V. y Vega, Z.

2020 "Discursos y estrategias en los grupos sikuris femeninos en el sur peruano: la experiencia de warmi sikuri awka sisa 
en Arequipa, Perú (2018-2019)". En Diálogo Andino 63: 151-160. Universidad de Tarapacá. Chile.

Geertz, C.

1989 El antropólogo como autor. Paidós, Barcelona.

Hamon, P.

1972 "Pour un statut sémiologique du personnage". En Littérature 6. París.

Hayner, P.

2008 Verdades innombrables: el reto de las comisiones de la verdad. Fondo de Cultura Económica, México.

Internacional, A.

2010 Comisionar la justicia. Las comisiones de la verdad y la justicia penal, https://doc.es.amnesty.org/ms-opac/ recordmedia/1@000022589/object/28843/raw (3 diciembre 2020).

Jara, R. y Vidal, H.

1986 Testimonio y literatura.Universidad de Minnesota, Minneapolis.

Jave, I.

2010 El Impacto público de la Comisión de la Verdad y Reconciliación 2001-2003. Tesis de Licenciatura. UNMSM, Lima.

Lefranc, $\mathrm{S}$.

2009 "La invención de certidumbres en el abandono de la violencia política: El ejemplo de las comisiones de la verdad". En Violencia y transiciones políticas a finales del siglo XX: Europa del Sur - América Latina, editado por Sophie Baby y Eduardo González, pp. 3-14. Casa de Velázquez, Madrid.

Losada, $\mathrm{M}$.

2007 Análisis de la controversia desplegada en medios de prensa respecto del informe de la CVR: avatares de una lucha pulsional. Tesis de Maestría. PUCP, Lima.

Macedo, G.

2008 Oralidad y memoria en canto de sirena. Hipocampo, Lima.

Manrique, $\mathrm{N}$.

2003 El tiempo del miedo. En La violencia política en el Perú 1980-1996, https://www.verdadyreconciliacionperu. com/admin/files/articulos/952_digitalizacion.pdf (10 abril 2015).

May, R.

2013 "Truth" and truth commissions in Latin America. En Investigación \& Desarrollo, 21: 494-512. Universidad del Norte, Barranquilla.

Mendoza, R., Alvarado, S. y Arroyo A.

2020 "Jóvenes quechuas del sur andino del Perú desde una mirada decolonial”. En Diálogo Andino 61:141-151. Universidad de Tarapacá. Chile.

Prada, R.

1986 "De lo testimonial al testimonio. Notas para un deslinde del discurso-testimonio". En Testimonio y literatura, editado por R. Jara y H. Vidal. Universidad de Minnesota, Minneapolis.

Ramos, E.

2009 Corporificación y testimonio de la CVR en los andes centrales: el caso de Huasahuasi. Tesis de Licenciatura. UNMSM, Lima.

Rendon, $\mathrm{S}$.

2019 "Capturing correctly: A reanalysis of the indirect capture-recapture methods in the Peruvian Truth and Reconciliation Commission", Research \& Politics 6 doi. org/10.1177/2053168018820375

Rodríguez, Silvia

2010 "Política del testimonio y reconocimiento en las comisiones de la verdad guatemalteca y peruana: En torno a la figura del "indio subversivo"”. Revista Crítica De Ciências Sociais, 88:23-55, doi:10.4000/rccs.1697

Rorty, R.

1998 Objetividad, relativismo y verdad. Paidós, Barcelona.

Silva Santisteban, R.

2008 El factor asco. Basurización simbólica y discursos autoritarios en el Perú. PUCP, Lima.

Saucedo, C.

2012 La literatura de la violencia política en el Perú(19802000): planteamientos narrativos y opciones éticas. Tesis de Doctorado. Brown University, Providence.

Theodosíadis, F.

1996 Literatura testimonial. Análisis de un discurso periférico. Cooperativa Editorial Magisterio, Bogotá.

Tudela, A.

2013 CVR: El monopolio de la verdad (5 noviembre), http://altavoz.pe/2013/08/28/opinion/cvr-el-monopoliode-la-verdad-por-adriana-tudela-gutierrez (20 noviembre 2015).

Vargas Llosa, M.

2003 "La verdad sospechosa". Revista Caretas (25 setiembre), Lima.

Vásquez, M. y Carrasco, A.

2018 "Mujeres y espacio público: las asociaciones indígenas femeninas aymaras de la ciudad de Arica”. En Diálogo Andino 56: 53-62. Universidad de Tarapacá. Chile.

Viera, $\mathrm{S}$.

2009 Imaginario andino y representación femenina en el testimonio Hijas de Kavillaca. Tesis de Licenciatura. UNMSM: Lima.

Zapata, A.

2010 La Comisión de la Verdad y Reconciliación y los medios de comunicación. Ayacucho y Lima. Instituto de Estudios Peruanos, Lima.

Zumthor, P.

1991 Introducción a la poesía oral. Taurus, Madrid.

\section{Notas}

1 La CVR aplicó el método de Estimación de Múltiples Sistemas.

2 Desde 2015, el Lugar de la Memoria tiene a disposición testimonios presentados en las audiencias públicas, https:// www.youtube.com/playlist?list=PLxWwNVWh7uyZ0DDN6wmy-fQ18fhNeng4 (Consulta: agosto 2015).

3 Conformaban una fuerza especial de la Policía.
$4 \quad$ Partido Comunista Peruano Sendero Luminoso.

5 "Todos los documentos producidos por la CVR, y a [sic] que a su vez han servido de sustento para la elaboración de este Informe Final, tienen como característica común provenir de una fuente oral. Todos ellos constituyen declaraciones hechas sobre cómo se vivió la violencia política desde diversos sectores. Por lo tanto, las declaraciones 
grabadas fueron transcritas fielmente y luego trasladadas a un formato digital. Este es el último soporte al que se ha recurrido para la redacción del Informe Final" (CVR 2003: I:40).

$6 \quad \mathrm{Al}$ respecto, Umberto Eco dice que: "Nosotros pensamos que en el mundo real debe valer el principio de Verdad (Truth), mientras que en los mundos narrativos debe valer el principio de Confianza (Trust)". Sin embargo, "también en el mundo real el principio de Confianza es tan importante como el principio de Verdad" (1996: 98).

7 Para Hamon el personaje est autant une reconstruction $d u$ lecteur qu'une construction du texte. Por tanto, la narrativa de los hechos cargará de significados que serán asumidos por dicho personaje.

8 Testimonios recogidos por la CVR para la redacción del IF que se encuentran en la Defensoría del Pueblo de Lima, Perú. 